\section{Rapid Population Growth of a Critically Endangered Carnivore}

\author{
M. B. Grenier, ${ }^{1,2 *}$ D. B. McDonald, ${ }^{1}$ S. W. Buskirk ${ }^{1}$
}

$\mathrm{E}$ ndangered species taken captive for breeding and then reintroduced to the wild commonly fail to produce self-sustaining populations (1). Such costly failures result from the persistence of the environmental factors that caused the species to become endangered, the effects of inbreeding in small populations, and the behavioral and physiological consequences of a captive environment. However, the first reintroduced population of the most endangered mammal species in North America, the blackfooted ferret (Mustela nigripes), is recovering rapidly in the Shirley Basin of Wyoming after a lag that seemed to portend population extinction.

The population recovery is notable because the bottleneck of the 1980s reduced genetic variability (2) and captive breeding affected various phenotypic traits (3). Further, endangered vertebrates commonly exhibit "slow" life history strategies $(4,5)$, producing low rates of population increase, unlike the $35 \%$ annual increase estimated by our matrix population model for the period 2003-2006. Remarkably, an even higher annual rate of increase, 59\% $(r=$ $0.47)$, was estimated from an exponential fit to the minimum number alive for the period 2000 2006 (Fig. 1). Also, two potentially devastat- ing infectious diseases, plague and canine distemper, occurred shortly after the releases. Notably, the primary prey at this site is the white-tailed prairie dog (Cynomys leucurus), which is considered suboptimal because it hibernates for extended periods and has low population densities (5).

The last known wild population of ferrets, discovered in 1981 near Meeteetse, Wyoming, formed the basis for the captive breeding program (5). From seven genetic founders in 1987, over 4800 juveniles have been produced, and many were reintroduced to sites in the ferret's historical range. Shirley Basin received 228 captive-born animals during 1991-1994 (Fig. 1). There, diseases triggered a decline; fewer than 25 ferrets were observed in 1996. By 1997, only five ferrets were found, and monitoring efforts were intermittent over the next 5 years; population extinction seemed imminent. In 2003, however, surveys revealed a surprising increase to 52 animals, and monitoring intensified. Three seasons of demographic data now permit a markrecapture estimate of population size $[\hat{N}=223$, $95 \%$ confidence interval (CI) is 192 to 401 ] within the 8100-ha study area, which includes only about $14 \%$ of the contiguous prairie dog habitat.

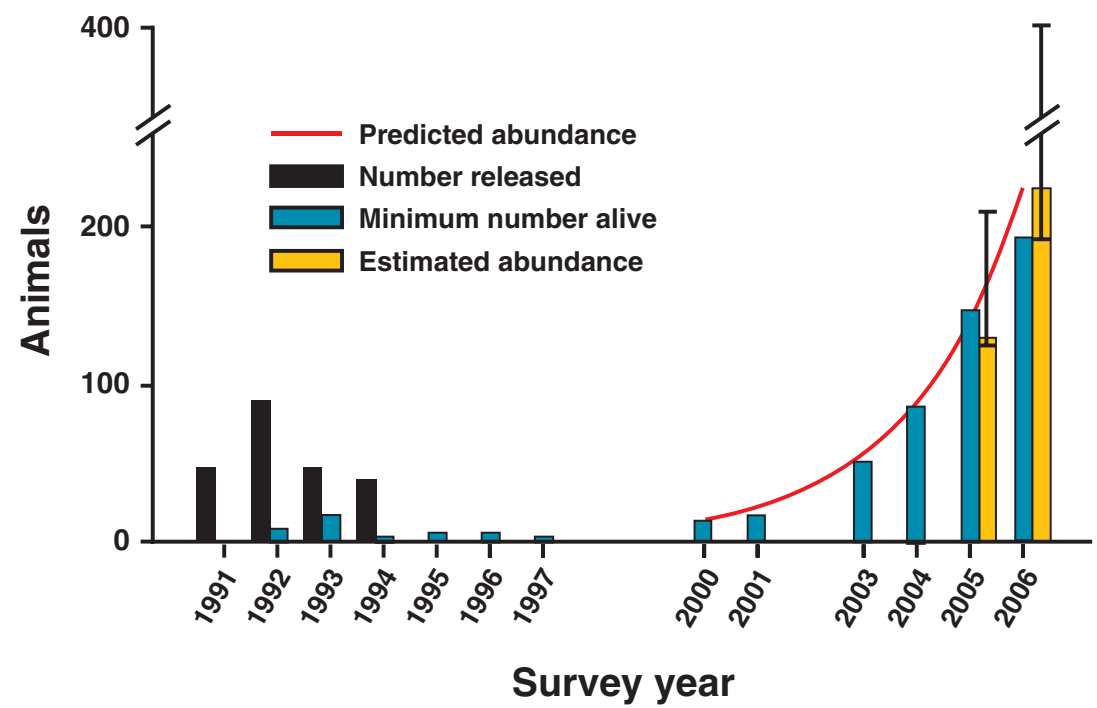

Fig. 1. Rapid population growth of black-footed ferrets in Shirley Basin, Wyoming, since 2000. Releases of captive-born animals ended in 1994, and abundance was so low by 1997 that monitoring was intermittent during 1998-2002 (no data for 1998-99 or 2002). Since 2003, more-intensive monitoring has revealed a rapidly growing population [223 animals in 2006 ( $95 \% \mathrm{Cl} 192$ to 401)], which has expanded beyond the study area boundaries. The predicted abundance is exponential growth fitted to the minimum number alive $(r=0.47)$. The estimated population growth rate $(\lambda)$, from our matrix population model, is 1.35 .

The species' potential for rapid population growth seems to contradict the slow life history strategy common to endangered vertebrates: low fecundity, high longevity, and high age at first reproduction (4). A matrix population model (6) based on our estimates of vital rates (including birthrates, survival rates, and mortality rates) revealed unexpected attributes (7). Matrix-based elasticity analysis showed that success in the first year of life is the key to demographic success. Elasticities assess the impact on the population growth rate $(\lambda)$ of proportional changes in the vital rates ( 6 ); for the black-footed ferret, more than half of the total elasticity is attributable to survival $\left(e_{21}=0.27\right)$ and fertility $\left(e_{11}=0.31\right)$ through the first year of life (fig. S1). Thus, early survival and recruitment are the crucial factors in this animal's life history, rather than the later adult survival that commonly matters to endangered species (4).

Black-footed ferrets have bred successfully in the wild for 7.5 ( $\pm 3.8 \mathrm{SD})$ generations (fig. S1), largely obviating fears that inbreeding depression or captive propagation would impair population establishment or short-term persistence (3). Vulnerabilities to infectious diseases and potential declines of prairie dog populations remain serious concerns. We suggest, however, that management could include more opportunistic and widespread reintroduction attempts without short-term postrelease monitoring. Although some attempts may not yield immediate success, the Shirley Basin example shows that species recovery is possible, given the ferret's capacity to persist at low population levels and to increase rapidly in favorable environments.

References and Notes

1. B. Griffith, J. M. Scott, ]. W. Carpenter, C. Reed, Science 245, 477 (1989)

2. S. M. Wisely, S. W. Buskirk, M. A. Fleming, D. B. McDonald, E. A. Ostrander, J. Hered. 93, 231 (2002).

3. S. M. Wisely et al., Anim. Conserv. 8, 321 (2005).

4. A. Purvis, ]. L. Gittleman, G. Cowlishaw, G. M. Mace, Proc. R. Soc. London Ser. B 267, 1947 (2000).

5. J. M. Lockhart, E. T. Thorne, D. R. Gober, in Recovery of the Black-Footed Ferret: Progress and Continuing Challenges, J. E. Roelle, B. J. Miller, ]. L. Godbey, D. E. Biggins, Eds. (U.S. Geological Survey, Reston, VA, 2006), pp. 6-19.

6. H. Caswell, Matrix Population Models (Sinauer Associates, Sunderland, MA, 2001).

7. Materials and methods are available on Science Online.

8. We thank C. Martinez del Río and M. Kauffman for helpful reviews. The project was supported by the Wyoming Game and Fish Department, the U.S. Fish and Wildlife Service, and private landowners.

Supporting Online Material

www.sciencemag.org/cgi/content/full/317/5839/779/DC1 Materials and Methods

Fig. S1

References

4 May 2007; accepted 19 June 2007

10.1126/science. 1144648

${ }^{1}$ Department of Zoology and Physiology, University of Wyoming, 1000 East University Avenue, Laramie, WY 82071, USA. 'Wyoming Game and Fish Department, 260 Buena Vista Drive, Lander, WY 82520, USA.

*To whom correspondence should be addressed. E-mail: martin.grenier@wgf.state.wy.us 